\title{
The Research of The Disturbance of Lightning Strike on Rogowski Coil Current Transformer According to Wavelet Analysis
}

\author{
LIU Guan-qi, SHAO Long, HU Ting \\ Department of Electrical Engineering \\ North China Electric Power University \\ Baoding, China \\ shaolong211@126.com
}

\begin{abstract}
Although there are many Rogowski coil current transformers being widely used, its stability and accuracy of measurement is not very good due to the effects of various factors. In practice, there are still some new interfering factors. In this paper, the principle of a new interference factors is analyzed, and the appropriate solution is put forward. The new interference is that when the power system is struck by lightning strike or over-voltage, the induced electromotive force of secondary side of the Rogowski current transformer is significantly interfered because of the fluctuation of capacitive coupling. So it will raise the measured current greatly and cause the measurement error. At last, the protective relaying will trip incorrectly. In this paper, the wavelet transform method is used to analyze the current of the transformer in normal conditions. Then the article analyzes the increased measured current caused by lightning strike and grid faults. And according to the results, the differences will be found which can be used to judge whether the increased current is caused by lightning strike or the grid faults.
\end{abstract}

Keywords-electronic current transformer, Rogowski coil, Wavelet Analysis, lightning strike

\section{INTRODUCTION}

Electronic transformer is an important equipment in power system. It can provide current and voltage signal for devices such as power measurement , control and protection. Its accuracy and reliability is closely related to the stability、 security and economy of power system ${ }^{[1][2]}$.

In this paper, I want to solve a problem of Rogowski current transformer in practical application. It is when the lightning strike or operation overvoltage occurs to the power system, the current value of secondary side of Rogowski current transformer will changed greatly duo to its own structure ${ }^{[3]}$. The mutation on wave is approximate with the current wave when the fault occurs, which will lead to the misoperation of protection devices, because the fault of the network is considered to be the reason of the current rise. The problem is widely existed among all the Rogowski current transformer, but there is no effective method to solve it ${ }^{[4]}$.

\section{FOURIER ANALYSIS AND WAVELETS ANALYSIS}

Fourier analysis can meet most demands, but it is a change as a whole, it can be used only in time domain and frequency domain and it may lose information of time. So, Fourier transform has its own shortcoming: there is no way to extract information during a certain period or a certain frequency. When the signal is not smooth or time-varying, Fourier transform can not perform well because it has no partial characteristic of signal.

Using Fourier transform, we can hardly distinguish whether the current rise is caused by the grid faults or the lightning strike, we can also hardly distinguish whether the condition is lightning strike with faults or lightning strike without faults. So, I analyze the current value of secondary side of Rogowski current transformer with Wavelets Analysis. Wavelets Transform is a partial analysis method with which the windows of time and frequency can change. Wavelet is a function, its mean value is zero and its energy is partial within both the time domain and frequency domain. Its wave is oscillation waveform, which is positive and negative alternating and attenuating to zero at both ends ${ }^{[5][6]}$

In this paper, I use db40 Wavelet in Daubechies Wavelet ${ }^{[7]}$. First, I analyze the normal current signal using db40 wavelet, then, I analyze the fault current. At last, I analyze the lightning strike over-current. And then find out the differences in different conditions. So we can provide the effective methods to protection device.

\section{FAULT ANALYSIS}

\section{A Analysis when steady operation}

First, do 5 layers wavelet decomposition to the current signal when the power system is steady operation with $\mathrm{db} 40$ wavelet. Then the detail coefficients are reconstructed. The wave of every layer of reconstruction shows in Fig.1. The amplified picture of the first layer of reconstruction shows in Fig.2. From Fig.2, we can see the amplitude of high-frequency part of steady current signal do not exceed 0.15 . 


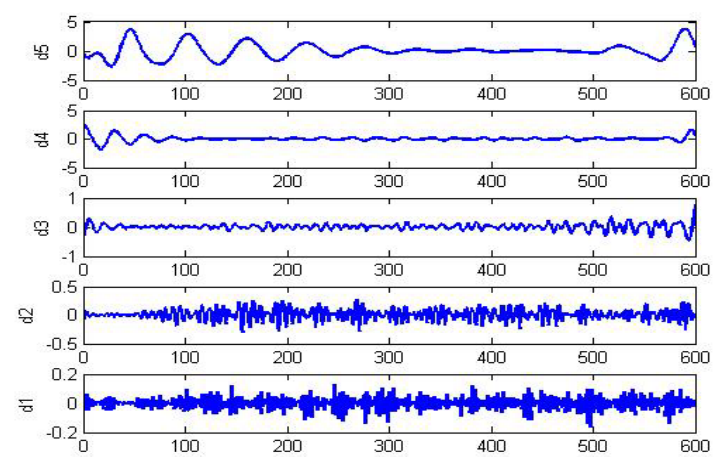

Fig.1 The details of 5 layers Wavelet Analysis 细节系数

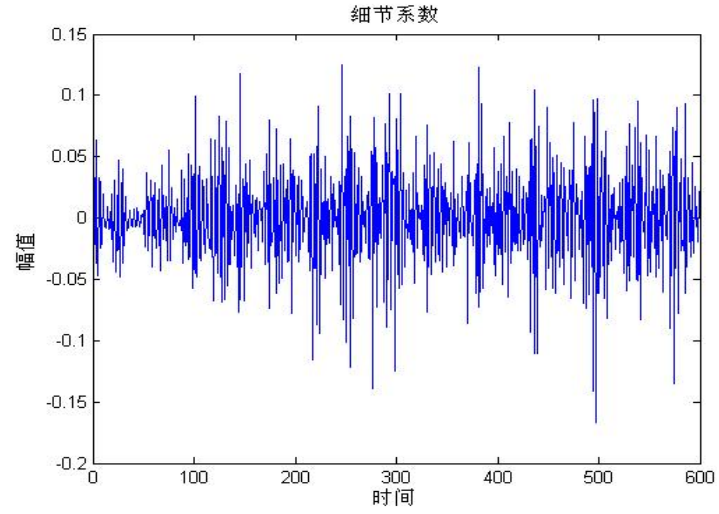

Fig.2 The detail of the first layer Wavelet Analysis

\section{$\mathrm{B}$ The analysis of single-phase fault}

I also use $\mathrm{db} 40$ wavelet to analyze the current signal of single-phase-to-ground fault. To find out the commonalities of details of the first layer in different time when the single-phase-to-ground fault happens and to prevent the appearance of special case, I analyze 5 single-phase faults, and these faults happen at 5 different time: $20 \mathrm{~ms} 、 26 \mathrm{~ms}$ 、 30ms、34ms、38ms.

For single-phase-to-ground faults at 5 different times, do 5 layers Wavelet Analysis. We can find the outcomes of Wavelet Analysis are different due to the faults happen at different time. But they have same tendency: during a period of time after fault happens, the amplitude obviously exceeds the normal value.

Take the details of the first layer of Wavelet Analysis, which is shown in Fig.3. From the 5 pictures, we can see when the single-phase-to-ground fault happens to the system, the current of transient process of power system contains a large number of complex high-frequency components. These components will exist within $10 \mathrm{~ms}$ after the fault happens. We can see all the 5 pictures in Fig. 3 that the amplitudes obviously exceed the normal value in Fig.2. It continues for more than $10 \mathrm{~ms}$, and it significantly reduced after $15 \mathrm{~ms}$. Which is a obvious feature to distinguish the fault to the system.

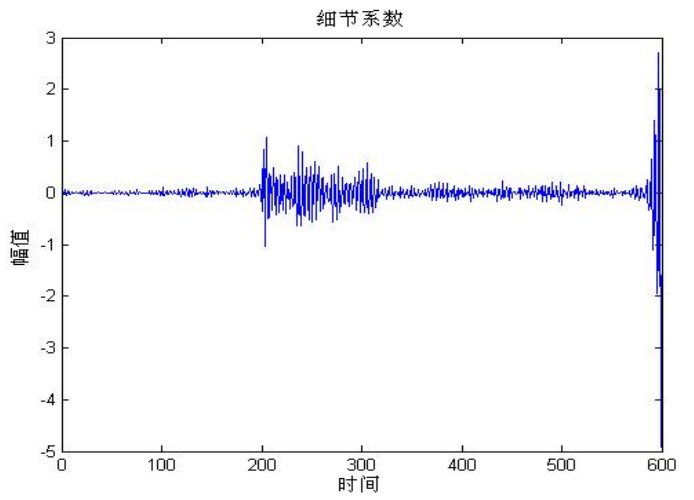

a: the detail of first layer of Wavelet Analysis of fault occurs at 20ms

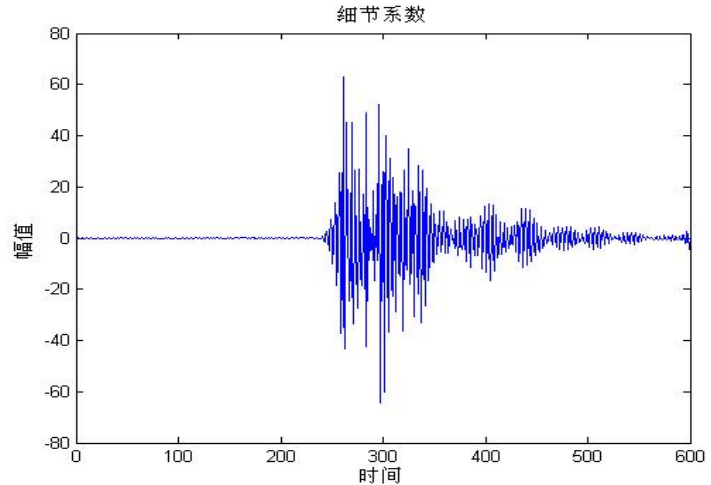

b: the detail of first layer of Wavelet Analysis of fault occurs at $26 \mathrm{~ms}$ 细节系数

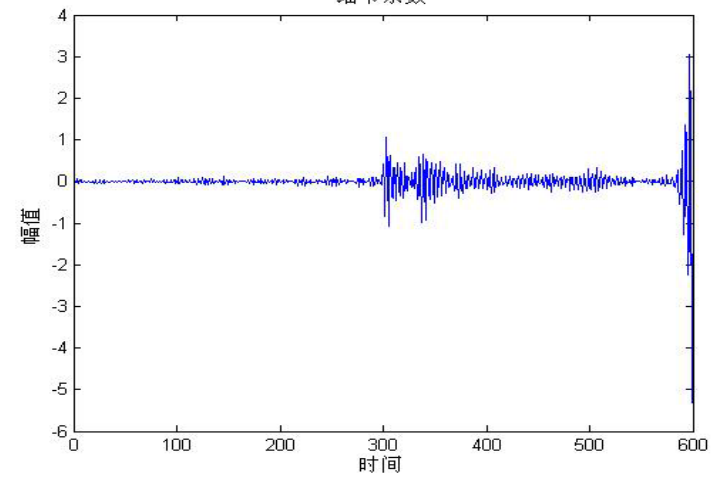

c: the detail of first layer of Wavelet Analysis of fault occurs at $30 \mathrm{~ms}$

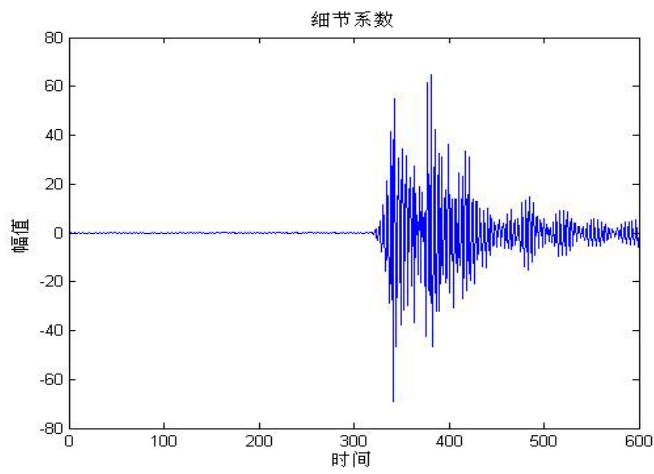

d: the detail of first layer of Wavelet Analysis of fault occurs at $34 \mathrm{~ms}$ 


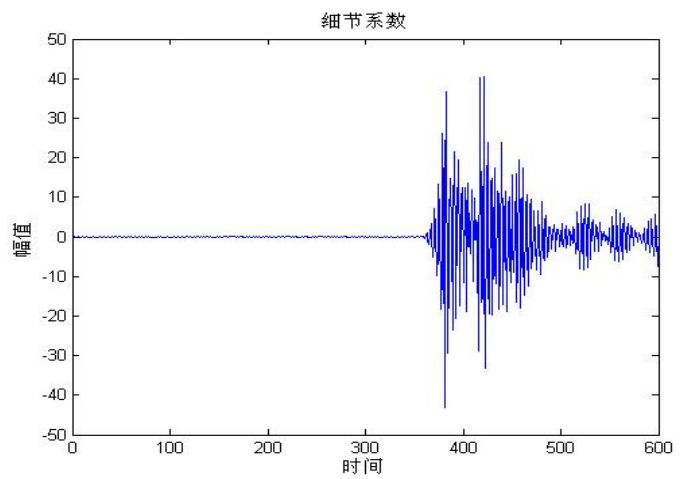

e: the detail of first layer of Wavelet Analysis of fault occurs at $38 \mathrm{~ms}$ Fig. 3 the details of the first layer of Wavelet Analysis

C The analysis of double-phase and trible-phase faults.

To continue to analyze, I take double-phase fault of $\mathrm{AB}$, $\mathrm{BC}$ and CA. Take double- phase-to-ground fault of $\mathrm{AB}, \mathrm{BC}$ and CA. Take trible-phase-to-ground fault. All of these faults happen at $20 \mathrm{~ms}, 26 \mathrm{~ms}, 30 \mathrm{~ms}, 34 \mathrm{~ms}$ and $38 \mathrm{~ms}$. Take 5 layers Wavelet Analysis using db40 Wavelet, from the picture of the first layer of Wavelet Analysis, we can find the high frequency component exists within 10ms after fault happens. This is the commonality of all the faults current. It is also an important characteristic I make use of in this paper. Because there are too many data and graphics, so I just list the relative graphics of AC double-phase-to-ground fault.

It is shown in Fig.5 that the details of 5 layers of Wavelet Analysis of A-phase and C-phase. We can see the details of different fault phases are not the same at the same fault time, but they have the same trend. In order to observe and analyze conveniently, the details of the first layer Wavelet Analysis are shown in Fig.6.

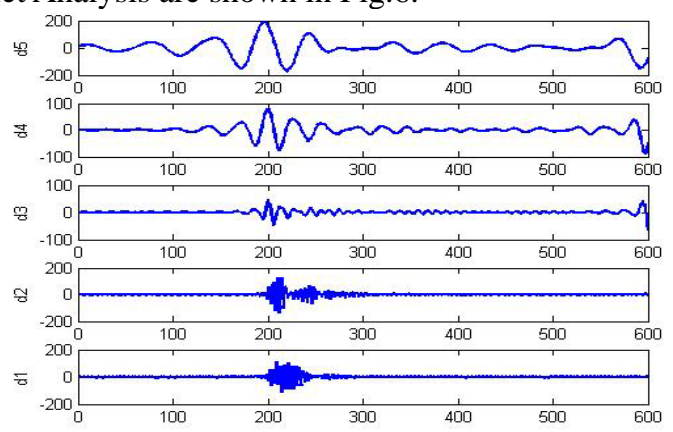

a: the details of Wavelet Analysis of A phase

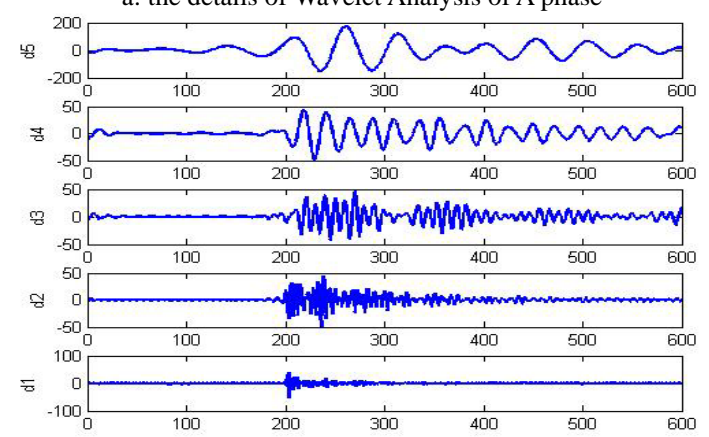

b: the details of Wavelet Analysis of C phase Fig. 5 the details of 5 layers of Wavelet Analysis when AC double-phase-to-ground fault

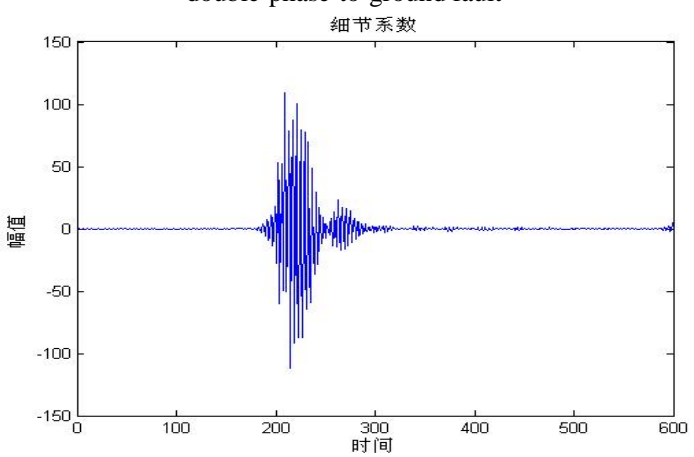

a: the detail of the first layer Wavelet Analysis of A phase

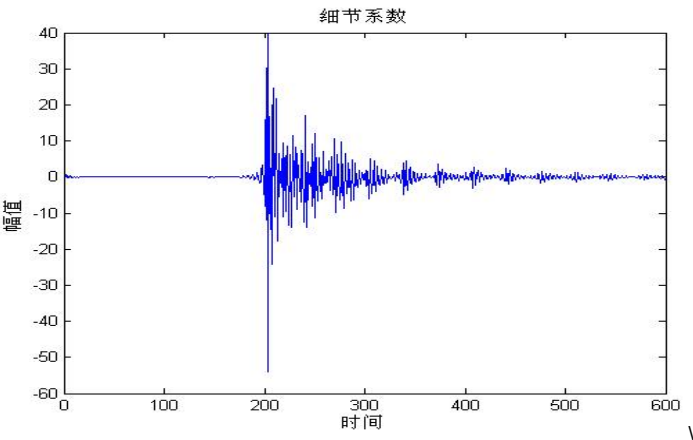

b: the detail of the first layer Wavelet Analysis of $\mathrm{C}$ phase Fig. 6 the details of the first layer Wavelet Analysis

\section{ANALYSIS OF THE CURRENT RISE CAUSED BY LIGHTNING STRIKE}

Take 558kV lightning impulse zero-drift experiment on Rogowski current transformer. Through collector, I get the current data of secondary side of Rogowski current transformer.

I superimpose the interfering current signals on the normal current signals, and then, take 5 layers Wavelet Analysis with db40 Wavelet. For conveniently analyzing, I enlarge the first layer detail of Wavelet Analysis, which is shown in Fig.8. In the picture, maximum amplitude point is the time of lightning strike. It is obvious that around the lightning strike, the energy value is large and centralized, subsequently, it decays rapidly to normal value.

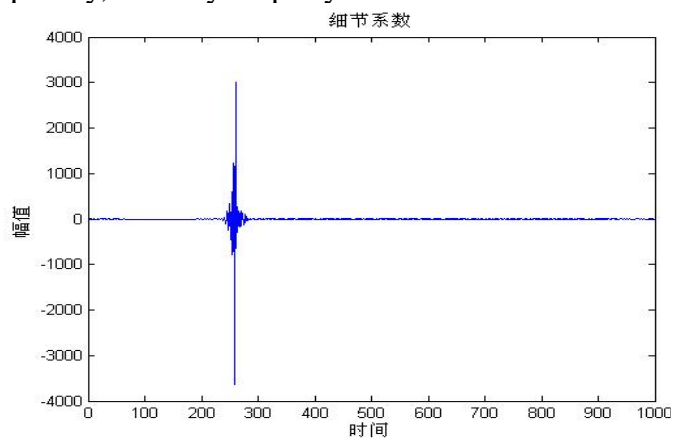

Fig.8 the detail of first layer Wavelet Analysis superimposed with lightning strike 
When the power system suffers lightning strike and accompanied by faults, I also take Wavelet Analysis as before. I enlarge the first layer detail of Wavelet Analysis, which is shown in Fig.9. We can see from the picture that when the lightning strike happens, the energy value is large and centralized, however, it is different from condition of just lightning strike.

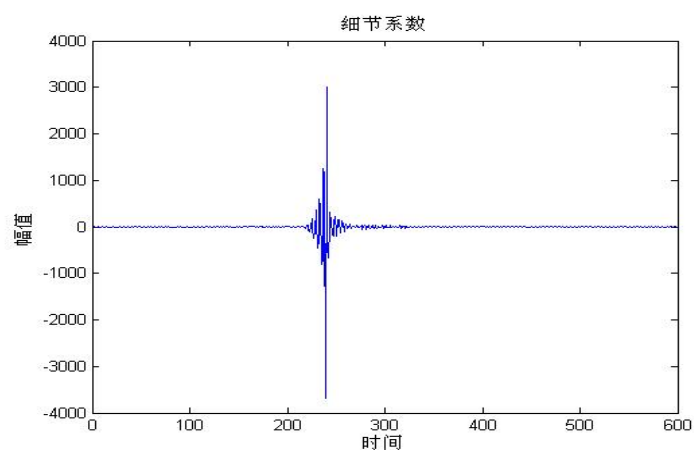

Fig.9 the detail of first layer Wavelet Analysis when lightning strike accompanied by fault

Compared with Fig.8, in Fig.9, between $5 \mathrm{~ms}$ and 10ms, there still a part of amplitudes exceed the normal value though they are relatively smaller. The region with relatively smaller amplitudes is caused by the high frequency in fault current. Restricted by the proportion in Fig.9, the phenomena is not very obvious, but it is really an important feature.

\section{$\mathrm{V}$ CONCLUSION}

Through a large number of experimental analysis, I can make the conclusion that when the fault happens (including fault caused by lightning strike), the energy amplitudes of first layer Wavelet Analysis exceed the normal value within $10 \mathrm{~ms}$ after fault happens. While it is only when the lightning strike happens, the energy amplitudes of first layer Wavelet Analysis mainly concentrate around the mutation and decay to the normal value within $5 \mathrm{~ms}$ after fault happens. In this paper, it is this difference that I utilize to distinguish whether the rise of measured current is caused by lightning strike. And then decide whether the protection devices acting or not.

\section{REFERENCES}

[1] HU Xue-hao, Smart Grid--A Development Trend of Future Power Grid[J]. Power System Technology. 2009, 33(14): 1-5

[2] GB/T 20840. 8-2007 the 8 part: Electronic current transformer[S]. 2007

[3] LUO Su-nan, TIAN Zhao-bo, ZHAO Xi-cai. Performance Analysis of Air-core Current Transformer[J]. Proceedings of the CSEE,2004, 24(3):108-113.

[4] ZHOU Wen-zhong, ZHAO Guo-sheng, LI Hai-yang. Error Analysis And Improved Method of Rogowski Coil[J]. Power System Protection and Control, 2009,37(20): 99- 103.

[5] XiongJie. Real Color Image Enhanced by Illumination-Reflectance Model and Wavelet Transform[J]. 2009 Intemational Forum on Information Technology and Applieations, IFITA 2009 Proeessings: 691-695.

[6] Ingrid Daubeehies. Ten Lectures on Wavelets [M]. Society for Industrial and Applied Mathematics. 1992

[7] Daubeehies I.Orthonormal Bases of Eompactly Supported Wavelets[A], Comm. Pure and Appl ,Math, 1989, 41(7): 909-996 